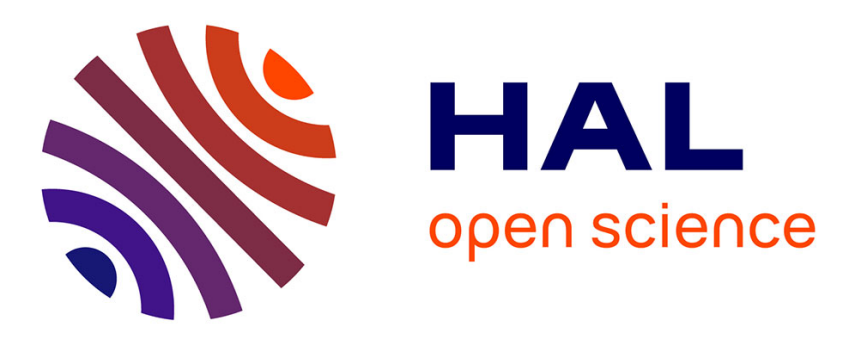

\title{
Laser operation of cleaved single-crystal plates and films of Tm:KY(MoO4)2
}

Anna Volokitina, Pavel Loiko, Anatoly Pavlyuk, Sami Slimi, Rosa Maria Solé, Ezzedine Ben Salem, Esrom Kifle, Josep Maria Serres, Uwe Griebner, Valentin Petrov, et al.

\section{To cite this version:}

Anna Volokitina, Pavel Loiko, Anatoly Pavlyuk, Sami Slimi, Rosa Maria Solé, et al.. Laser operation of cleaved single-crystal plates and films of Tm:KY(MoO4)2. Optics Express, 2020, 28 (7), pp.9039. 10.1364/OE.384260 . hal-03346144

\author{
HAL Id: hal-03346144 \\ https://hal.science/hal-03346144
}

Submitted on 7 Oct 2021

HAL is a multi-disciplinary open access archive for the deposit and dissemination of scientific research documents, whether they are published or not. The documents may come from teaching and research institutions in France or abroad, or from public or private research centers.
L'archive ouverte pluridisciplinaire HAL, est destinée au dépôt et à la diffusion de documents scientifiques de niveau recherche, publiés ou non, émanant des établissements d'enseignement et de recherche français ou étrangers, des laboratoires publics ou privés. 


\title{
Laser operation of cleaved single-crystal plates and films of $\mathrm{Tm}: \mathrm{KY}\left(\mathrm{MoO}_{4}\right)_{2}$
}

\author{
Anna Volokitina, ${ }^{1,2}$ Pavel Loiko, ${ }^{3}$ Anatoly Pavlyuk, ${ }^{4}$ Sami Slimi, $, 1,5$ \\ Rosa Maria Solé, ${ }^{1}$ EZzedine Ben Salem, ${ }^{4}$ Esrom Kifle, ${ }^{1}$ Josep Maria \\ Serres, ${ }^{1,6}$ UWe Griebner, ${ }^{7}$ Valentin Petrov, ${ }^{7}$ Magdalena Aguiló, ${ }^{1}$ \\ Francesc Díaz, ${ }^{1}$ and Xavier Mateos ${ }^{1, *}$
}

${ }^{1}$ Física i Cristal-lografia de Materials i Nanomaterials (FiCMA-FiCNA)-EMaS, Dept. Química Física i Inòrganica, Universitat Rovira i Virgili (URV), Campus Sescelades, E-43007 Tarragona, Spain ${ }^{2}$ ITMO University, 49 Kronverkskiy Pr., 197101 St. Petersburg, Russia

${ }^{3}$ Centre de recherche sur les Ions, les Matériaux et la Photonique (CIMAP), UMR 6252 CEA-CNRSENSICAEN, Université de Caen, 6 Boulevard du Maréchal Juin, 14050 Caen Cedex 4, France

${ }^{4}$ A. V. Nikolaev Institute of Inorganic Chemistry, Siberian Branch of Russian Academy of Sciences, 3 Lavrentyev Ave., Novosibirsk 630090, Russia

${ }^{5}$ I.P.E.I. of Monastir, Unit of Materials and Organic Synthesis Monastir 5019, UR17ES31, Tunisia

${ }^{6}$ Eurecat, Centre Tecnologic de Catalunya, Unitat Advanced Manufacturing Systems (AMS), Campus Sescelades, E-43007 Tarragona, Spain

${ }^{7}$ Max Born Institute for Nonlinear Optics and Short Pulse Spectroscopy, Max-Born-Str. 2a, D-12489 Berlin, Germany

*xavier.mateos@urv.cat

\begin{abstract}
We report on the crystal growth, spectroscopy and first laser operation of a novel double molybdate compound - Tm:KY $\left(\mathrm{MoO}_{4}\right)_{2}$. This orthorhombic (sp. gr. Pbna) crystal exhibits strong anisotropy of the spectroscopic properties due to its layered structure. The maximum stimulated emission cross-section for the ${ }^{3} \mathrm{~F}_{4} \rightarrow{ }^{3} \mathrm{H}_{6}$ transition is $2.70 \times 10^{-20} \mathrm{~cm}^{2}$ at $1856 \mathrm{~nm}$ with a bandwidth of $>110 \mathrm{~nm}$ (for $\boldsymbol{E} \| \boldsymbol{b}$ ). The lifetime of the ${ }^{3} \mathrm{~F}_{4}$ state is $2.29 \mathrm{~ms}$. Crystalline films and plates (thickness down to $70 \mu \mathrm{m}$ ) of high optical quality are obtained by mechanical cleavage along the (100) plane. Continuous-wave diode-pumped laser operation is achieved in such thin films and plates yielding a maximum output power of $0.88 \mathrm{~W}$ at $\sim 1.9 \mu \mathrm{m}$ with a slope efficiency of $65.8 \%$ and a linearly polarized laser output. Vibronic lasing is demonstrated at $\sim 2.06 \mu \mathrm{m}$. Tm: $\mathrm{KY}\left(\mathrm{MoO}_{4}\right)_{2}$ is promising for microchip and thin-disk lasers.
\end{abstract}

(C) 2019 Optical Society of America under the terms of the OSA Open Access Publishing Agreement

\section{Introduction}

Monoclinic (sp. gr. $C 2 / c$ ) double tungstate (DT) crystals, $\mathrm{KRE}\left(\mathrm{WO}_{4}\right)_{2}$ (where $\mathrm{RE}=\mathrm{Gd}, \mathrm{Y}, \mathrm{Lu}$ ), doped with rare-earth ions $\left(\mathrm{RE}^{3+}\right)$, and, in particular, with trivalent thulium $\left(\mathrm{Tm}^{3+}\right)$ ions are known for efficient lasing in the eye-safe spectral range of $\sim 2 \mu \mathrm{m}$ according to the ${ }^{3} \mathrm{~F}_{4} \rightarrow{ }^{3} \mathrm{H}_{6}$ electronic transition [1-3]. This is due to the high achievable Tm doping concentrations, strong cross-relaxation for neighboring $\mathrm{Tm}^{3+}$ ions, ${ }^{3} \mathrm{H}_{4}\left(\mathrm{Tm}_{1}\right)+{ }^{3} \mathrm{H}_{6}\left(\mathrm{Tm}_{2}\right) \rightarrow{ }^{3} \mathrm{~F}_{4}\left(\mathrm{Tm}_{1}\right)+{ }^{3} \mathrm{~F}_{4}\left(\mathrm{Tm}_{2}\right)$ [4], even at moderate doping levels, broad and intense emission bands at $\sim 2 \mu \mathrm{m}$ with polarized light [5], weak non-radiative relaxation from the upper laser level $\left({ }^{3} \mathrm{~F}_{4}\right)$ and Raman activity. The host crystals themselves also provide suitable thermo-optical properties enabling microchip laser operation [6,7]. Monoclinic DTs exhibit a polymorphic phase transformation below the melting point. Thus, they are typically grown by the Top-Seeded Solution Growth (TSSG) method (from the flux) [1].

Such attractive spectroscopic properties are also expected for their double molybdate (DMo) counterparts, $\operatorname{KRE}\left(\mathrm{MoO}_{4}\right)_{2}$. One representative of this crystal family is the potassium yttrium double molybdate, $\mathrm{KY}\left(\mathrm{MoO}_{4}\right)_{2}$ [8]. It belongs to the orthorhombic crystal class (sp. gr. Pbna) and does not exhibit polymorphism [9]. Thus, it can be easily grown by the Czochralski $(\mathrm{Cz})$ method (from the melt). Moreover, $\mathrm{KY}\left(\mathrm{MoO}_{4}\right)_{2}$ features a layered structure further 
enhancing the polarization-anisotropy of vibronic $[10,11]$ and spectroscopic properties $[14,15]$ and leading to a perfect cleavage feature that can be utilized in microchip or thin-film lasers [14]. The structure of undoped $\mathrm{KY}\left(\mathrm{MoO}_{4}\right)_{2}$ is known [8].

The previous studies of laser properties of $\mathrm{RE}^{3+}$-doped $\mathrm{KY}\left(\mathrm{MoO}_{4}\right)_{2}$ crystals focused solely on $\mathrm{Nd}^{3+}$ ions. The first laser operation of $\mathrm{Nd}: \mathrm{KY}\left(\mathrm{MoO}_{4}\right)_{2}$ at the wavelengths of $1.067 \mu \mathrm{m}$ and $1.349 \mu \mathrm{m}$ was obtained in the free-running regime (flashlamp pumping) $[15,16]$. Continuouswave (CW) operation with bulk crystals was later achieved in [17,18]. Kaminski et al. also proposed the concept of a thin-film or a belt-shaped laser using thin crystalline films (thickness: down to $50 \mu \mathrm{m})$ of $\mathrm{Nd}: \mathrm{KY}\left(\mathrm{MoO}_{4}\right)_{2}$ pumped by flash-lamps and $\mathrm{Ar}^{+}$ion laser [14].

Recently, efficient lasers operating at $\sim 1 \mu \mathrm{m}$ based on single-crystal plates were demonstrated using other cleaving crystals such as $\mathrm{Yb}: \mathrm{LuPO}_{4}$ or $\mathrm{Yb}: \mathrm{BaGd}_{2}\left(\mathrm{MoO}_{4}\right)_{4}[19,20]$.

In the present work, we report on the crystal growth by the Czochralski method, structural and spectroscopic characterization as well as the first laser operation of a novel representative of the DMo crystal family - the orthorhombic Tm:KY $\left(\mathrm{MoO}_{4}\right)_{2}$ crystal.

\section{Crystal growth and structure}

\subsection{Crystal growth}

The crystal growth was performed by the Low Temperature Gradient (LTG) Cz method [21]. The Tm:KY $\left(\mathrm{MoO}_{4}\right)_{2}$ crystal melts at $\sim 1243 \mathrm{~K}$. The starting materials for preparing the growth charge were $\mathrm{Y}_{2} \mathrm{O}_{3}$ (purity: $5 \mathrm{~N}$ ), $\mathrm{Tm}_{2} \mathrm{O}_{3}(4 \mathrm{~N}), \mathrm{MoO}_{3}(4 \mathrm{~N})$ and $\mathrm{K}_{2} \mathrm{CO}_{3}(5 \mathrm{~N})$ taken for the composition $100 \mathrm{~mol} \% \mathrm{KY}_{0.97} \mathrm{Tm}_{0.03}\left(\mathrm{MoO}_{4}\right)_{2}-5-7 \mathrm{~mol} \% \mathrm{~K}_{2} \mathrm{Mo}_{3} \mathrm{O}_{10}$. Potassium trimolybdate $\left(\mathrm{K}_{2} \mathrm{Mo}_{3} \mathrm{O}_{10}\right)$ was added to prevent partial dissociation of the melt and to stabilize the growth process. The raw materials were carefully mixed and placed in a Pt crucible with a cylindrical shape (diameter: $70 \mathrm{~mm}$, height: $120 \mathrm{~mm}$ ). The crucible was first heated until $1320 \mathrm{~K}$ in air and kept at this temperature for $2-3 \mathrm{~h}$ to homogenize the melt. Then, the melt was cooled to $\sim 1240 \mathrm{~K}$ (the starting growth temperature). The crucible was placed in a three-zone resistive heating furnace having good bottom and top heat insulation [21]. A seed prepared from an undoped $\mathrm{KY}\left(\mathrm{MoO}_{4}\right)_{2}$ crystal was oriented orthogonal to the cleavage plane (i.e., along the [100] crystallographic axis). It was rotated at 20 r.p.m. (revolutions per minute); the pulling rate was $1-2 \mathrm{~mm} / \mathrm{h}$; the cooling rate was $\sim 2 \mathrm{~K} /$ day. The temperature gradient in the melt was below 3 $\mathrm{K} / \mathrm{cm}$ as measured by a $\mathrm{Pt} / \mathrm{Pt}-\mathrm{Rh}$ thermocouple along the crystal growth direction. After the growth process was completed, the crystal was removed from the melt and slowly cooled down to room temperature (RT, $293 \mathrm{~K}$ ). No post-grown annealing was applied.

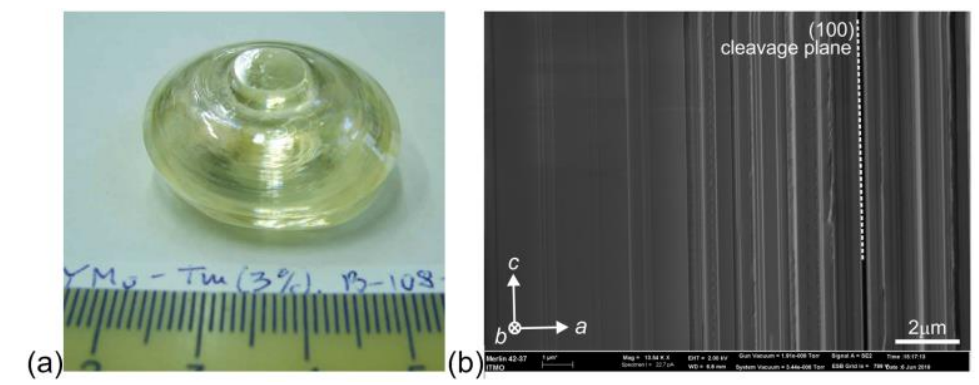

Fig. 1. (a) Photograph of the as-grown 3 at.\% Tm:KY $\left(\mathrm{MoO}_{4}\right)_{2}$ crystal boule. The growth direction is along the [100] axis (vertical); (b) Scanning Electron Microscope (SEM) image of the side surface of a cleaved single-crystal film indicating the crystallographic directions.

The as-grown 3 at.\% Tm:KY $\left(\mathrm{MoO}_{4}\right)_{2}$ crystal boule is shown in Fig. 1(a). The $\mathrm{Tm}^{3+}$ concentration was calculated to be $N_{\mathrm{Tm}}=1.95 \times 10^{20} \mathrm{~cm}^{-3}$ (assuming a segregation coefficient $\left.K_{\mathrm{Tm}} \approx 1\right)$. The crystal boule had a donut shape and contained no cracks and inclusions. The crystal had a slight yellowish coloration due to the $\mathrm{Tm}^{3+}$ doping. Tm:KY $\left(\mathrm{MoO}_{4}\right)_{2}$ exhibits a perfect natural cleavage along the crystallographic (100) plane (i.e., orthogonal to the growth 
direction in the present work), as verified by single-crystal X-ray diffraction (XRD). The orientation of the [010] and [001] axes was also determined by single-crystal XRD. It can be also found in a different way. The (100) cleaved thin crystal plates of Tm:KY $\left(\mathrm{MoO}_{4}\right)_{2}$ brake under bending along the [001] axis. Along the orthogonal [010] axis, the plates exhibit an elastic deformation. An anisotropy of thermal properties of Tm:KY $\left(\mathrm{MoO}_{4}\right)_{2}$ in the (100) plane also determines a slight ellipticity of the cross-section of the crystal boule with the principal directions along the [010] and [001] axes.

A Scanning Electron Microscope (SEM) image of the fracture edge of a mechanically cleaved single-crystal plate of Tm:KY $\left(\mathrm{MoO}_{4}\right)_{2}$ is shown in Fig. 1(b). Note that the whole boule of Tm:KY $\left(\mathrm{MoO}_{4}\right)_{2}$ has a single-crystalline nature. The fracture of crystal-plates occurs along the [001] axis. The SEM image reveals the natural cleavage feature as the fracture edge represents multiple "stairs" running parallel to the $c$-axis in the (100) plane.

\subsection{Crystal structure and Raman spectra}

The structure and phase purity of Tm:KY $\left(\mathrm{MoO}_{4}\right)_{2}$ were confirmed by powder XRD, see Fig. 2(a). Tm:KY $\left(\mathrm{MoO}_{4}\right)_{2}$ belongs to the orthorhombic centrosymmetric crystal class (sp. gr. Pbna $-\mathrm{D}^{14}{ }_{2 \mathrm{~h}}$, No. 60 ). No traces of any other impurity phases are found. The lattice constants for the 3 at.\% Tm-doped crystal were determined using the Rietveld refinement to be $a=$ 18.2012(9) $\AA, b=7.9301(5) \AA, c=5.0666(4) \AA, \alpha=\beta=\gamma=90^{\circ}$, the calculated density $\rho_{\text {calc }}$ is $4.0897(4) \mathrm{g} / \mathrm{cm}^{3}$ (the number of the structural units $Z=4$ ). The reduced chi-squared value of $\chi^{2}$ $=\left(R_{\mathrm{wp}} / R_{\mathrm{exp}}\right)^{2}$ for this fit is $1.802\left(R_{\mathrm{wp}}=8.65 \%, R_{\exp }=4.80 \%\right)$. The initial set of atomic coordinates for undoped $\mathrm{KY}\left(\mathrm{MoO}_{4}\right)_{2}$ was taken from [8].

The structure of Tm:KY( $\left(\mathrm{MoO}_{4}\right)_{2}$ consists of continuous belts of edge-sharing distorted $\left[\mathrm{YO}_{8}\right]$ octahedra arranged parallel to the $\boldsymbol{b}$-axis. In the $\boldsymbol{a}-\boldsymbol{b}$ plane, they share corners with the $\left[\mathrm{MoO}_{4}\right]$ tetrahedra. The radicals $\left[\mathrm{Y}\left(\mathrm{MoO}_{4}\right)_{2}\right]^{-}$form porous layers parallel to the $\boldsymbol{b}-\boldsymbol{c}$ plane. The linkage of these layers along the $\boldsymbol{a}$-axis is weak, which explains the excellent cleavage along the (100) plane. $\mathrm{Tm}^{3+}$ ions substitute for $\mathrm{Y}^{3+}$ in a single site (coordination number (C.N.) by oxygen is VIII, $\mathrm{C}_{2}$ symmetry). This is favored by the closeness of ionic radii of $\mathrm{Tm}^{3+}(0.994 \AA)$ and $\mathrm{Y}^{3+}(1.019 \AA)$.
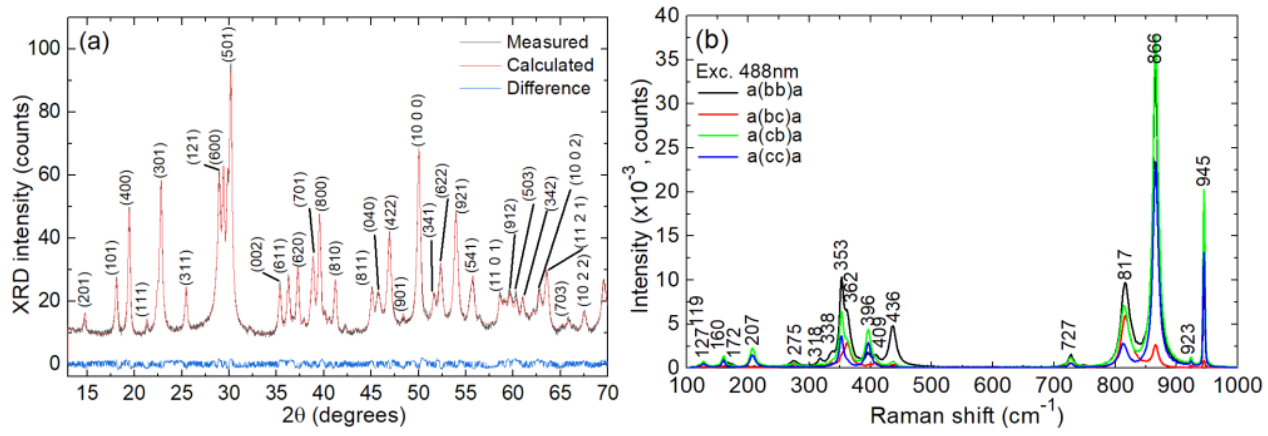

Fig. 2. (a) Rietveld refinement of the X-ray powder diffraction (XRD) pattern of the 3 at.\% Tm:KY $\left(\mathrm{MoO}_{4}\right)_{2}$ crystal; numbers indicate the Miller's indices $(h k l)$ (sp. gr. Pbna); (b) Polarized Raman spectra of the Tm:KY $\left(\mathrm{MoO}_{4}\right)_{2}$ crystal for the $\boldsymbol{a}(i j) \boldsymbol{a}$ geometries, where $i, j=\boldsymbol{b}$ or $\boldsymbol{c}$ (Porto's notations), $\lambda_{\mathrm{exc}}=488 \mathrm{~nm}$.

The polarized Raman spectra were measured using a Renishaw inVia confocal Raman microscope with a $\times 50$ objective. The excitation wavelength $\lambda_{\text {exc }}$ was $488 \mathrm{~nm}_{\left(\mathrm{Ar}^{+} \text {ion laser }\right.}$ line). The spectral resolution was $\sim 1 \mathrm{~cm}^{-1}$. The Raman spectra of an (100)-oriented plate from the Tm:KY $\left(\mathrm{MoO}_{4}\right)_{2}$ crystal are shown in Fig. 2(b). The spectra contain bands localized in three ranges and having different intensity. The low-frequency range (at $<275 \mathrm{~cm}^{-1}$ ) contains weak vibrations related to translational $\left(\mathrm{T}^{\prime}\right)$ modes of $\mathrm{K}, \mathrm{Y} \mid \mathrm{Tm}$ and Mo and rotational (R) lattice modes. Internal modes are observed at higher frequencies. The second intermediate-frequency range at $318-436 \mathrm{~cm}^{-1}$ exhibits bands of medium intensity related to the bending $(\delta)$ vibrations 
of the oxygen bridged $\left[\mathrm{MoO}_{4}\right]$ tetrahedra. Finally, the high-frequency range, 727-945 $\mathrm{cm}^{-1}$, contains intense modes due to the stretching $(v)$ vibrations of $\left[\mathrm{MoO}_{4}\right]$. The most intense and strongly polarized Raman peak appears at $865.6 \mathrm{~cm}^{-1}$ with a full width at half maximum (FWHM) of $10.5 \mathrm{~cm}^{-1}$. It is assigned to one of the internal (v) vibrations of $\left[\mathrm{MoO}_{4}\right]$. The maximum phonon energy of Tm:KY $\left(\mathrm{MoO}_{4}\right)_{2}$ is $945 \mathrm{~cm}^{-1}$. More details can be found elsewhere $[10,11]$.

\section{Spectroscopic study}

\subsection{Experimental}

The $\mathrm{KY}\left(\mathrm{MoO}_{4}\right)_{2}$ crystal is orthorhombic and, thus, optically biaxial. The frame of the optical indicatrix axes $(\mathrm{X}, \mathrm{Y}, \mathrm{Z})$ coincides with the $(\boldsymbol{a}, \boldsymbol{b}, \boldsymbol{c})$ crystallographic frame (not necessarily respectively). Only a mean value of the refractive index $\langle n\rangle \approx 2$ is known [15]. Thus, the anisotropic absorption and luminescence properties were characterized for the $\boldsymbol{E} \| \boldsymbol{a}, \boldsymbol{b}, \boldsymbol{c}$ light polarizations. All the spectroscopic studies were performed at RT (293 K).

For measuring the absorption and luminescence spectra, we used a $\sim 1 \mathrm{~mm}$-thick cleaved crystal plate. The absorption spectra were measured for the available light polarizations $\boldsymbol{E} \| \boldsymbol{b}$ and $\boldsymbol{E} \| \boldsymbol{c}$ using a Varian CARY 5000 spectrophotometer and a Glan-Taylor polarizer. The spectral resolution was $0.1-0.5 \mathrm{~nm}$. It was complicated to prepare a polished sample oriented orthogonal to the cleavage plane thus accessing the $\boldsymbol{E} \| \boldsymbol{a}$ polarization in absorption.

The luminescence spectra at $\sim 2 \mu \mathrm{m}$ for the polarizations $\boldsymbol{E} \| \boldsymbol{a}, \boldsymbol{b}, \boldsymbol{c}$ were measured using an optical spectrum analyzer (AQ6375B, Yokogawa, spectral resolution: $1 \mathrm{~nm}$ ) and a Glan-Taylor polarizer. The spectral response of the set-up was calibrated employing a quartz iodine lamp. The excitation source was a CW Ti:Sapphire laser tuned to $\sim 802 \mathrm{~nm}$.

The luminescence decay of $\mathrm{Tm}^{3+}$ ions was studied using a $1 / 4 \mathrm{~m}$ monochromator (Oriel 77200), an InGaAs detector and a $8 \mathrm{GHz}$ digital oscilloscope (DSA70804B, Tektronix). The luminescence was excited by the output of a ns optical parametric oscillator tuned to $\sim 802 \mathrm{~nm}$ (Horizon, Continuum).

\subsection{Optical absorption and luminescence}

The absorption spectrum of the Tm:KY $\left(\mathrm{MoO}_{4}\right)_{2}$ crystal for light polarizations $\boldsymbol{E} \| \boldsymbol{b}$ and $\boldsymbol{E} \| \boldsymbol{c}$ is shown in Fig. 3(a). In the spectrum, the absorption bands are due to transitions of $\mathrm{Tm}^{3+}$ ions from the ground-state $\left({ }^{3} \mathrm{H}_{6}\right)$ to the excited-states $\left({ }^{3} \mathrm{~F}_{4}\right.$ to $\left.{ }^{1} \mathrm{D}_{2}\right)$. There is no color center absorption in the visible. The UV absorption edge is found at $\lambda_{\mathrm{UV}}=327 \mathrm{~nm}$ (for $\boldsymbol{E} \| \boldsymbol{c}$ ) and $340 \mathrm{~nm}$ (for $\boldsymbol{E}$ $\| \boldsymbol{b})$, corresponding to an optical bandgap $E_{\mathrm{g}}$ of $3.64-3.80 \mathrm{eV}$.
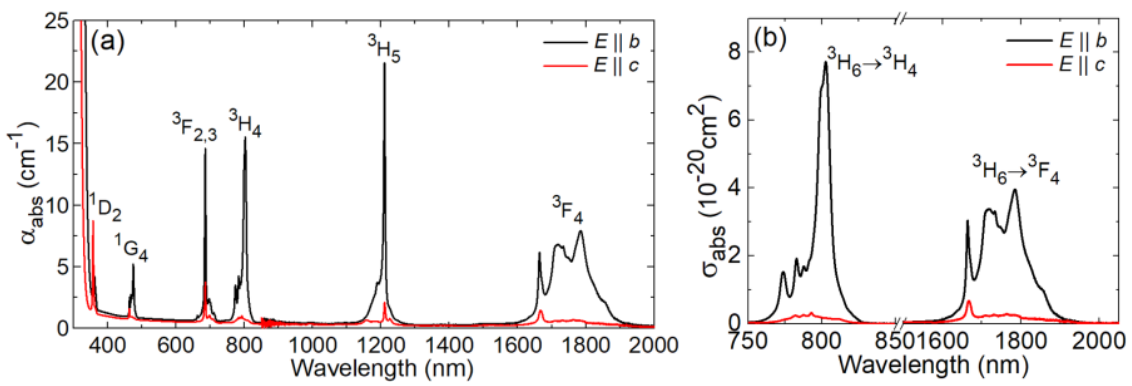

Fig. 3. Absorption of the Tm: $\mathrm{KY}\left(\mathrm{MoO}_{4}\right)_{2}$ crystal: (a) full absorption spectrum; (b) absorption cross-sections, $\sigma_{\text {abs }}$, for the ${ }^{3} \mathrm{H}_{6} \rightarrow{ }^{3} \mathrm{~F}_{4}$ and ${ }^{3} \mathrm{H}_{4}$ transitions for polarizations $\boldsymbol{E} \| \boldsymbol{b}$ and $\boldsymbol{E} \| \boldsymbol{c}$.

The absorption cross-sections, $\sigma_{\mathrm{abs}}$, for the ${ }^{3} \mathrm{H}_{6} \rightarrow{ }^{3} \mathrm{H}_{4}$ and ${ }^{3} \mathrm{H}_{6} \rightarrow{ }^{3} \mathrm{~F}_{4}$ transitions are shown in Fig. 3(b). For the ${ }^{3} \mathrm{H}_{6} \rightarrow{ }^{3} \mathrm{H}_{4}$ one, the maximum $\sigma_{\text {abs }}$ is $7.70 \times 10^{-20} \mathrm{~cm}^{2}$ at $802.8 \mathrm{~nm}$ and the corresponding FWHM of the absorption peak is $10.0 \mathrm{~nm}$ (for $\boldsymbol{E} \| \boldsymbol{b}$ ). For the second available light polarization $(\boldsymbol{E} \| \boldsymbol{c}), \sigma_{\mathrm{abs}}$ is by one order of magnitude smaller: $0.32 \times 10^{-20} \mathrm{~cm}^{2}$ at 792.9 $\mathrm{nm}$. This transition is suitable for pumping of $\mathrm{Tm}^{3+}$ ions, e.g., by commercial and high-power 
AlGaAs laser diodes (the "conventional" pump scheme). The maximum $\sigma_{\text {abs }}$ value for the ${ }^{3} \mathrm{H}_{6}$ $\rightarrow{ }^{3} \mathrm{H}_{4} \mathrm{Tm}^{3+}$ transition in $\mathrm{KY}\left(\mathrm{MoO}_{4}\right)_{2}$ is similar to that in monoclinic Tm: $\mathrm{KLu}\left(\mathrm{WO}_{4}\right)_{2}, \sigma_{\mathrm{abs}}=$ $9.5 \times 10^{-20} \mathrm{~cm}^{2}$ at $793.6 \mathrm{~nm}$ [1] however providing a FWHM of the absorption peak of $1.7 \mathrm{~nm}$ (light polarization: $\boldsymbol{E} \| N_{\mathrm{p}}$ ). As a result, Tm:KY( $\left(\mathrm{MoO}_{4}\right)_{2}$ is more suitable for diode-pumping because of weaker sensitivity to the temperature drift of the diode emission wavelength. For the ${ }^{3} \mathrm{H}_{6} \rightarrow{ }^{3} \mathrm{~F}_{4} \mathrm{Tm}^{3+}$ transition in $\mathrm{KY}\left(\mathrm{MoO}_{4}\right)_{2}, \sigma_{\text {abs }}$ reaches $3.95 \times 10^{-20} \mathrm{~cm}^{2}$ at $1785 \mathrm{~nm}$ (again for $\boldsymbol{E} \| \boldsymbol{b}$ ). This transition is suitable for in-band pumping of $\mathrm{Tm}^{3+}$ ions directly to the upper laser level, e.g., by erbium Raman fiber lasers emitting at $\sim 1.7 \mu \mathrm{m}$ [22].

The notable anisotropy of the absorption cross-sections in the (100) plane cannot be assigned to the layered structure and is most probably related to the low symmetry of the $\mathrm{Tm}^{3+}$ site $\left(\mathrm{C}_{2}\right)$.

The stimulated-emission (SE) cross-sections, $\sigma_{\mathrm{SE}}$, for the ${ }^{3} \mathrm{~F}_{4} \rightarrow{ }^{3} \mathrm{H}_{6}$ transition of $\mathrm{Tm}^{3+}$ were calculated using the Füchtbauer-Ladenburg (F-L) formula [23]:

$$
\sigma_{\mathrm{SE}}^{i}(\lambda)=\frac{\lambda^{5}}{8 \pi\langle n\rangle^{2} \tau_{\mathrm{rad}} c} \frac{W_{i}(\lambda)}{(1 / 3) \sum_{i=a, b, c} \int_{c} \lambda W_{i}(\lambda) \mathrm{d} \lambda},
$$

where $\lambda$ is the light wavelength, $\langle n\rangle$ is the refractive index, $c$ is the speed of light, $\tau_{\text {rad }}$ is the radiative lifetime of the emitting state $\left({ }^{3} \mathrm{~F}_{4}\right), W_{i}(\lambda)$ is the measured luminescence spectrum for $i$-th polarization calibrated for the spectral response of the set-up and $i=\boldsymbol{a}, \boldsymbol{b}, \boldsymbol{c}$. The results are shown in Fig. 4(a). The maximum $\sigma_{\mathrm{SE}}$ is $2.70 \times 10^{-20} \mathrm{~cm}^{2}$ at $1856 \mathrm{~nm}$ with an emission bandwidth $(\mathrm{FWHM}$ ) of $>110 \mathrm{~nm}$ (for $\boldsymbol{E} \| \boldsymbol{b})$. Tm:KY $\left(\mathrm{MoO}_{4}\right)_{2}$ exhibits a notable anisotropy of the SE crosssections: the ratios $\sigma_{\mathrm{SE}}(\boldsymbol{b}): \sigma_{\mathrm{SE}}(\boldsymbol{c})=7.5$ and $\sigma_{\mathrm{SE}}(\boldsymbol{b}): \sigma_{\mathrm{SE}}(\boldsymbol{a})=5.7$ at $\sim 1.86 \mu \mathrm{m}$, which is a prerequisite for a linearly polarized laser output.
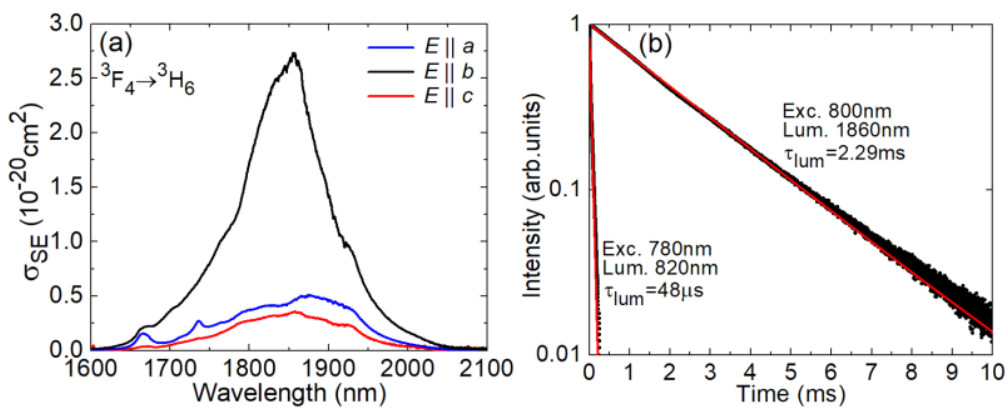

Fig. 4. Emission properties of the Tm: $\mathrm{KY}\left(\mathrm{MoO}_{4}\right)_{2}$ crystal: (a) stimulated-emission (SE) crosssections, $\sigma_{\mathrm{SE}}$, for the ${ }^{3} \mathrm{~F}_{4} \rightarrow{ }^{3} \mathrm{H}_{6}$ transition, light polarizations are $\boldsymbol{E} \| \boldsymbol{a}, \boldsymbol{b}, \boldsymbol{c}$; (b) luminescence decay curve from the ${ }^{3} \mathrm{~F}_{4}$ state, $\lambda_{\text {exc }}=800 \mathrm{~nm}, \lambda_{\text {lum }}=1860 \mathrm{~nm}$.

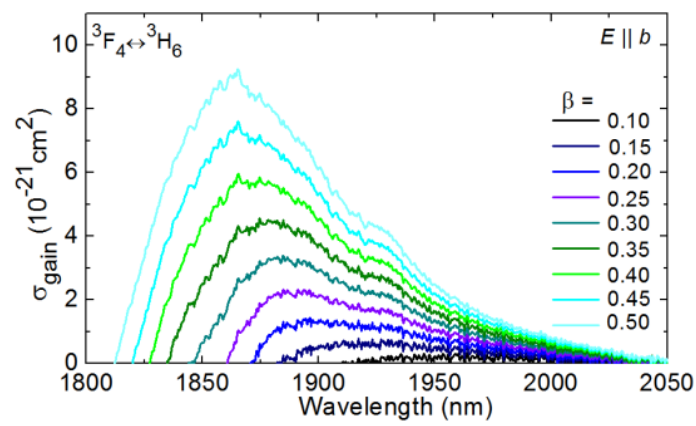

Fig. 5. Gain cross-sections, $\sigma_{\text {gain }}=\beta \sigma_{\mathrm{SE}}-(1-\beta) \sigma_{\text {abs }}$, for the ${ }^{3} \mathrm{~F}_{4} \leftrightarrow{ }^{3} \mathrm{H}_{6}$ transition of $\mathrm{Tm}^{3+}$ in $\mathrm{KY}\left(\mathrm{MoO}_{4}\right)_{2}: \beta=N_{2}\left({ }^{3} \mathrm{~F}_{4}\right) / N_{\mathrm{Tm}}$ is the inversion ratio, the light polarization is $\boldsymbol{E} \| \boldsymbol{b}$.

The luminescence decay from the ${ }^{3} \mathrm{~F}_{4}$ state is single-exponential yielding a luminescence lifetime $\tau_{\text {lum }}$ of $2.29 \mathrm{~ms}$, see Fig. 4(b). This agrees with the accommodation of $\mathrm{Tm}^{3+}$ ions in a 
single type of sites (symmetry: $\mathrm{C}_{2}$ ). The luminescence lifetime of the ${ }^{3} \mathrm{H}_{4}$ pump level is $48 \mu$ s. This value is expected to be quenched by the cross-relaxation. Both lifetimes were measured for thin (tens of $\mu \mathrm{m}$ ) films eliminating the effect of reabsorption (radiation trapping). Indeed, the $\tau_{\text {lum }}\left({ }^{3} \mathrm{~F}_{4}\right)$ value obtained using a crystal-plate was much longer, $3.35 \mathrm{~ms}$.

The ${ }^{3} \mathrm{~F}_{4} \rightarrow{ }^{3} \mathrm{H}_{6} \mathrm{Tm}^{3+}$ transition represents a quasi-three-level laser scheme with reabsorption losses. Thus, the gain cross-sections, $\sigma_{\mathrm{gain}}=\beta \sigma_{\mathrm{SE}}-(1-\beta) \sigma_{\mathrm{abs}}$, are typically calculated to conclude about the expected emission wavelength, where $\beta=N_{2}\left({ }^{3} \mathrm{~F}_{4}\right) / N_{\mathrm{Tm}}$ is the inversion ratio and $N_{2}$ is the population of the upper laser level $\left({ }^{3} \mathrm{~F}_{4}\right)$. The $\sigma_{\text {gain }}$ spectra for the high-gain light polarization $\boldsymbol{E} \| \boldsymbol{b}$ are shown in Fig. 5. They are relatively smooth and broad.

\section{Laser operation}

\subsection{Laser set-up}

For the laser experiments, we prepared two samples from the 3 at.\% Tm:KY $\left(\mathrm{MoO}_{4}\right)_{2}$ crystal. They were fabricated by mechanical cleaving the crystal using a thin razor blade placed along the (100) crystallographic plane. Only a slight pressure was applied to the blade producing the initial crack which further easily propagated through the crystal cross-section. The samples had a thickness $(t)$ of $70 \pm 5 \mu \mathrm{m}$ and $700 \pm 10 \mu \mathrm{m}$, referred further as a thin-film and a crystal-plate, respectively. The thickness was measured using a micrometer and confirmed by SEM for the thin-film. It was uniform along the sample cross-section within the specified error. The first sample exhibited elastic deformation at naked eye. No post-cleavage processing (e.g., polishing or coating) was applied. The clean aperture of the samples was more than $1 \mathrm{~cm}^{2}$. The samples were fabricated from the bulk crystal oriented by means of single-crystal XRD so that the orientation of the [010] and [001] axes was known.

The samples were placed in a compact plano-plano (microchip) cavity formed by a flat pump mirror (PM) coated for high transmission (HT) at the pump wavelength, $\sim 0.80 \mu \mathrm{m}$, and for high reflection (HR) at 1.8-2.1 $\mu \mathrm{m}$, and a set of flat output couplers (OCs) having a transmission $T_{\mathrm{OC}}$ of $0.1 \%-9 \%$ at the laser wavelength, Fig. 6(a). A special band-pass (BP) OC coated for $\mathrm{HT}$ at $<2 \mu \mathrm{m}$ and for partial reflection $\left(T_{\mathrm{OC}}=1.5 \%\right)$ at $2.05-2.20 \mu \mathrm{m}$ was also used. Both the PM and $\mathrm{OC}$ were gently pressed towards the crystalline sample, so that the geometrical cavity length $L_{\mathrm{cav}} \equiv t$. The laser element was passively cooled, Fig. 6(b).
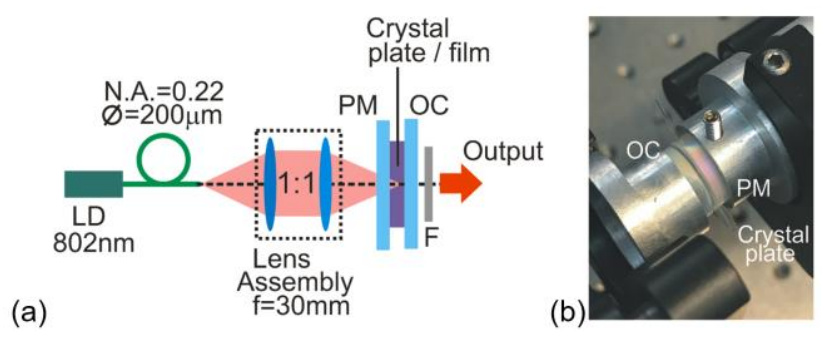

Fig. 6. (a) Scheme of the diode-pumped microchip Tm:KY( $\left(\mathrm{MoO}_{4}\right)_{2}$ lasers: $\mathrm{LD}$ - laser diode, $\mathrm{PM}$ - pump mirror, OC - output coupler, F - cut-off filter; (b) photograph of the laser.

The laser element was pumped by a fiber-coupled (fiber core diameter: $200 \mu \mathrm{m}$, N.A. $=$ $0.22) \mathrm{AlGaAs}$ laser diode emitting up to $17 \mathrm{~W}$ of unpolarized output at $802 \mathrm{~nm}\left(\mathrm{M}^{2} \approx 86\right)$. The incident pump power was limited to avoid optical damage at the crystal / mirror interfaces. The pump beam was collimated and focused into the laser element by a lens assembly (1:1 reimaging ratio, focal length $\mathrm{f}=30 \mathrm{~mm}$ ) resulting in a pump spot diameter $2 w_{\mathrm{P}}=200 \pm 10 \mu \mathrm{m}$. Due to the partial reflectivity of the OCs at the pump wavelength $(R \approx 40 \%)$, the pumping was in a double-pass. The total pump absorption was taken at its small-signal value, $\eta_{\mathrm{abs}, 0}=6.4 \%$ and $47.6 \%$ for the thin-film and crystal-plate, respectively. This value does not account for the possible ground-state bleaching; however, it does not overestimate the slope efficiency of the 
laser. The laser output was separated from the residual pump using a long-pass filter (FEL1000, Thorlabs).

\subsection{Laser performance}

First, we studied the laser performance of the crystal-plate $(t=700 \mu \mathrm{m})$, Fig. 7(a),(b). The laser generated a maximum output power of $0.88 \mathrm{~W}$ at $1840-1905 \mathrm{~nm}$ with a slope efficiency $\eta$ of $65.8 \%$ (vs. the absorbed pump power $P_{\text {abs }}$ ) and the laser threshold was at $P_{\text {abs }}=210 \mathrm{~mW}$ (for $T_{\mathrm{OC}}=5 \%$ ). For higher output coupling, the performance slightly deteriorated probably due to the upconversion losses. For all OCs, the input-output dependences were linear indicating weak thermal effects. The laser polarization was linear $(\boldsymbol{E} \| \boldsymbol{b})$; it was naturally selected by the anisotropy of the gain. Typical spectra of the laser emission are shown in Fig. 7(b). With the increase of $T_{\mathrm{OC}}$, the spectra experienced a blue-shift due to the quasi-three-level nature of the ${ }^{3} \mathrm{~F}_{4} \rightarrow{ }^{3} \mathrm{H}_{6} \mathrm{Tm}^{3+}$ laser scheme. For example, for small $T_{\mathrm{OC}}=1.5 \%$, the laser operated at 1970 $1978 \mathrm{~nm}$ and for high $T_{\mathrm{OC}}=9 \%$ - at $1826-1835 \mathrm{~nm}$. This behavior agrees well with the gain spectra for light polarization $\boldsymbol{E} \| \boldsymbol{b}$, Fig. 5.


Fig. 7. Diode-pumped laser performance of (100)-oriented cleaved (a,b) thin-film $(t=70 \mu \mathrm{m})$ and (c,d) crystal-plate $(t=700 \mu \mathrm{m}) 3$ at.\% Tm:KY $\left(\mathrm{MoO}_{4}\right)_{2}$ crystal: (a,c) input-output dependences, $\eta$ - slope efficiency; (b,d) typical spectra of the laser emission measured at maximum $P_{\text {abs. }}$. The laser polarization is $\boldsymbol{E} \| \boldsymbol{b}$.

By implementing the band-pass OC, laser emission beyond $2 \mu \mathrm{m}$ was achieved. The output power reached $0.34 \mathrm{~W}$ at $2047-2074 \mathrm{~nm}$ with $\eta=46.7 \%$ and a laser threshold of $205 \mathrm{~mW}$. Such a long wavelength emission is ascribed to the electron-phonon coupling with the lowenergy Raman modes of the $\mathrm{KY}\left(\mathrm{MoO}_{4}\right)_{2}$ lattice [24,25].

The second experiment consisted of inserting the crystal-film into the laser cavity, Fig. 7(c),(d). The maximum output power was $131 \mathrm{~mW}$ at $1801-1872 \mathrm{~nm}$ with $\eta=45.2 \%$ and a threshold of only $35 \mathrm{~mW}$ (for $T_{\mathrm{OC}}=1.5 \%$ ). The emission was linearly polarized $(\boldsymbol{E} \| \boldsymbol{b})$. With the increase of the output coupling, the laser threshold increased: from $13 \mathrm{~mW}$ for the smallest $T_{\mathrm{OC}}=0.1 \%$ up to $54 \mathrm{~mW}$ for $T_{\mathrm{OC}}=9 \%$ still remaining relatively low. The slope efficiency first increased with $T_{\mathrm{OC}}$ (so that the optimum transmission of the $\mathrm{OC}$ is expected to lie between $T_{\mathrm{OC}}$ $=0.1 \%$ and $1.5 \%$ ) and, furthermore, decreased for $T_{\mathrm{OC}}>1.5 \%$. The latter effect is probably due to stronger energy-transfer upconversion (ETU) associated with higher population of the upper 
laser level ${ }^{3} \mathrm{~F}_{4}$ (higher inversion rate $\beta$ ) at increased output coupling. The ETU has a direct influence on the laser threshold [26]. However, it also leads to a stronger heat dissipation and more severe thermo-optic effects in the gain medium thus affecting the slope efficiency in an indirect way.

The lower slope efficiency achieved with the crystal-film laser as compared to the crystalplate one is ascribed to higher passive losses originating from possible mechanical distortion and bending of the film. We expect that such losses can be eliminated by further optimizing the cleaving procedure.

The blue-shift of the emission spectra with the output coupling was also detected, Fig. 7(d). The spectra contained equidistant spectral lines separated by $\Delta \lambda=12.2 \mathrm{~nm}$ at $\sim 1.85 \mu \mathrm{m}$ (for $\left.T_{\mathrm{OC}}=1.5 \%-9 \%\right)$. This is ascribed to the etalon effect of the uncoated laser element. The free spectral range (FSR) of the Fabry-Perot etalon with a thickness $t$ and a refractive index $n_{\mathrm{g}}\left(n_{\mathrm{g}} \approx\right.$ $n$ assuming a weak dispersion) at normal incidence is $\Delta \lambda_{\mathrm{FSR}} \approx \lambda^{2} /\left(n_{\mathrm{g}} t\right)$. From this formula, we get the etalon thickness of $71 \mu \mathrm{m}$ for $n=2.0$ in good agreement with the measured thickness.

The Tm: $\mathrm{KY}\left(\mathrm{MoO}_{4}\right)_{2}$ lasers operated in the fundamental transverse mode. The beam quality parameters measured using an ISO-standard method employing a focusing lens $\mathrm{M}_{\mathrm{x}, \mathrm{y}}^{2}<1.2(x$ $=\boldsymbol{b}, y=\boldsymbol{c})$.

\section{Conclusion}

To conclude, the orthorhombic double molybdate crystal Tm:KY( $\left(\mathrm{MoO}_{4}\right)_{2}$ is a promising material for efficient $\sim 2 \mu \mathrm{m}$ lasers owing to its easy growth, high available doping levels, intense, broad and strongly polarized absorption and emission bands and Raman activity. The layered structure of $\mathrm{KY}\left(\mathrm{MoO}_{4}\right)_{2}$ promotes the anisotropy of its optical properties and allows one to fabricate easily laser-quality crystal plates and films with a thickness ranging from few $\mathrm{mm}$ down to tens of $\mu \mathrm{m}$. This feature is of interest for microchip and thin-disk lasers. In particular, the long lifetime of the upper laser level of $\mathrm{Tm}^{3+}$ is attractive for passively Qswitched sub-nanosecond microchip lasers. In the present work, we achieved $\sim 2 \mu \mathrm{m} C W$ laser action in single-crystal plates (sub-mm) and films (sub-100 $\mu \mathrm{m}$ ) featuring up to $65.8 \%$ slope efficiency and almost watt-level output for passively-cooled devices.

\section{Funding}

Spanish Government (MAT2016-75716-C2-1-R (AEI/FEDER,UE), Generalitat de Catalunya (2017SGR755); Russian Foundation for Basic Research (RFBR) (19-32-90199).

\section{Disclosures}

The authors declare no conflicts of interest.

\section{References}

1. V. Petrov, M. C. Pujol, X. Mateos, O. Silvestre, S. Rivier, M. Aguiló, R. M. Solé, J. Liu, U. Griebner, and F. Díaz, "Growth and properties of $\mathrm{KLu}\left(\mathrm{WO}_{4}\right)_{2}$, and novel ytterbium and thulium lasers based on this monoclinic crystalline host," Laser \& Photon. Rev. 1(2), 179-212 (2007).

2. X. Mateos, V. Petrov, J. Liu, M. C. Pujol, U. Griebner, M. Aguiló, F. Díaz, M. Galan, and G. Viera, "Efficient $2-\mu \mathrm{m}$ continuous-wave laser oscillation of $\mathrm{Tm}^{3+}: \mathrm{KLu}\left(\mathrm{WO}_{4}\right)_{2}$, , IEEE J. Quantum Electron. 42(10), 1008-1015 (2006).

3. A. E. Troshin, V. E. Kisel, A. S.Yasukevich, N. V. Kuleshov, A. A. Pavlyuk, E. B. Dunina, E.B. and A. A. Kornienko, "Spectroscopy and laser properties of $\mathrm{Tm}^{3+}: \mathrm{KY}\left(\mathrm{WO}_{4}\right)_{2}$ crystal," Appl. Phys. B 86(2), 287-292 (2007)

4. K. van Dalfsen, S. Aravazhi, C. Grivas, S. M. García-Blanco, and M. Pollnau, "Thulium channel waveguide laser with $1.6 \mathrm{~W}$ of output power and $\sim 80 \%$ slope efficiency," Opt. Lett. 39(15), 4380-4383 (2014).

5. Ò. Silvestre, M. C. M. Rico, F. Güell, M. Aguiló, and F. Díaz, "Thulium doped monoclinic $\mathrm{KLu}\left(\mathrm{WO}_{4}\right)_{2}$ single crystals: growth and spectroscopy,” Appl. Phys. B 87(4), 707-716 (2007).

6. M.S. Gaponenko, P.A. Loiko, N.V. Gusakova, K.V. Yumashev, N.V. Kuleshov, and A.A. Pavlyuk, "Thermal lensing and microchip laser performance of $N_{\mathrm{g}}$-cut $\mathrm{Tm}^{3+}: \mathrm{KY}\left(\mathrm{WO}_{4}\right)_{2}$ crystal," Appl. Phys. B 108(3), 603-607 (2012). 
7. J.M. Serres, X. Mateos, P. Loiko, K. Yumashev, N. Kuleshov, V. Petrov, U. Griebner, M. Aguiló, and F. Díaz, "Diode-pumped microchip Tm:KLu( $\left(\mathrm{WO}_{4}\right)_{2}$ laser with more than $3 \mathrm{~W}$ of output power," Opt. Lett. 39(14), 4247-4250 (2014).

8. R. F. Klevtsova, and S. V. Borisov, "X-ray structural study of the double molybdate $\mathrm{KY}\left(\mathrm{MoO}_{4}\right)_{2}$," Sov. Phys. Dokl. 12, 1095 (1968) [Transl. from Dokl. Akad. Nauk SSSR 177(6), 1333-1336 (1967)].

9. P. V. Klevtsov and R. F. Klevtsova, "Polymorphism of the double molybdates and tungstates of mono-and trivalent metals with the composition $\mathrm{M}^{+} \mathrm{R}^{3+}\left(\mathrm{EO}_{4}\right)_{2}$," J. Struct. Chem. 18(3), 339-355 (1977).

10. J. Hanuza, and L. Łabuda, "Polarized Raman and infrared spectra of a multilayer $\mathrm{KY}\left(\mathrm{MoO}_{4}\right)_{2}$ crystal," J. Raman Spectr. 11(4), 231-237 (1981).

11. J. Hanuza, and L. Macalik, "Polarized IR and Raman spectra of orthorhombic $\mathrm{KLn}\left(\mathrm{MoO}_{4}\right)_{2}$ crystals $(\mathrm{Ln}=\mathrm{Y}$, Dy, Ho, Er, Tm, Yb, Lu)," Spectrochim. Acta A: Mol. Spectr. 38(1), 61-72 (1982).

12. A. Volokitina, P. Loiko, E. Vilejshikova, X. Mateos, E. Dunina, A. Kornienko, N. Kuleshov, and A. Pavlyuk, "Eu $\mathrm{Eu}^{3+}: \mathrm{KY}\left(\mathrm{MoO}_{4}\right)_{2}$ : A novel anisotropic red-emitting material with a layered structure," J. Alloy Compd. 762, 786-796 (2018).

13. Y. Chen, Y. Lin, X. Gong, Q. Tan, Z. Luo, and Y. Huang, "Polarized spectral characteristics of $\mathrm{Nd}^{3+}: \mathrm{KY}\left(\mathrm{MoO}_{4}\right)_{2}$ crystal with perfect cleavage planes: a promising microchip gain medium," J. Opt. Soc. Am. B 24(3), 496-503 (2007).

14. A. A. Kaminskii and S. N. Bagayev, "Ribbon and sheet miniature crystal laser," Quantum Electron. 24(12), 1029-1030 (1994).

15. A. A. Kaminskii, P. V. Klevtsov, and A. A. Pavlyuk, "Stimulated emission from $\mathrm{KY}\left(\mathrm{MoO}_{4}\right)_{2}-\mathrm{Nd}^{3+}$ crystal laser," Phys. Status Solidi A 1(3), K91-K94 (1970).

16. A. A. Kaminskii, S. E. Sarkisov, and L. Li, "Investigation of stimulated emission in the ${ }^{4} \mathrm{~F}_{3 / 2} \rightarrow{ }^{4} \mathrm{I}_{13 / 2}$ transition of $\mathrm{Nd}^{3+}$ ions in crystals (III)," Phys. Status Solidi A 15(2), K141-K144 (1973).

17. A. A. Kaminskii, and H. R. Verdun, "New high power, high efficient quasi-CW and CW single-mode $\mathrm{KY}\left(\mathrm{MoO}_{4}\right)_{2}: \mathrm{Nd}^{3+}$ laser end-pumped by a GaAlAs laser-diode array," Phys. Status Solidi A 138(1), K49-K53 (1993).

18. P. Loiko, E. Kifle, J. M. Serres, X. Mateos, M. Aguiló, F. Díaz, E. Vilejshikova, N. Kuleshov, and A. Pavlyuk, "Efficient continuous-wave in-band pumped Nd:KY(MoO $)_{2}$ laser," Laser Phys. Lett. 15(6), 065002-1-5 (2018).

19. J. Liu, W. Han, X. Chen, D. Zhong, B. Teng, C. Wang, and Y. Li, "Spectroscopic properties and continuouswave laser operation of $\mathrm{Yb}: \mathrm{LuPO}_{4}$ crystal," Opt. Lett. 39(20), 5881-5884 (2014).

20. H. Zhu, Y. Chen, Y. Lin, X. Gong, Q. Tan, Z. Luo, and Y. Huang, "Growth, spectral properties, and laser demonstration of $\mathrm{Yb}^{3+}: \mathrm{BaGd}_{2}\left(\mathrm{MoO}_{4}\right)_{4}$ cleavage crystal," J. Appl. Phys. 101(6), 063109-1-8 (2007).

21. Y. A. Borovlev, N. V. Ivannikova, V. N. Shlegel, Y. V. Vasiliev, and V. A. Gusev, "Progress in growth of large sized BGO crystals by the low-thermal-gradient Czochralski technique," J. Cryst. Growth 229(1-4), 305-311 (2001).

22. P. Loiko, R. Thouroude, R. Soulard, L. Guillemot, G. Brasse, B. Guichardaz, A. Braud, A. Hideur, M. Laroche, H. Gilles, and P. Camy, "In-band pumping of Tm:LiYF 4 channel waveguide: a power scaling strategy for $\sim 2$ $\mu \mathrm{m}$ waveguide lasers," Opt. Lett. 44(12), 3010-3013 (2019).

23. B. Aull and H. Jenssen, "Vibronic interactions in Nd:YAG resulting in nonreciprocity of absorption and stimulated emission cross sections," IEEE J. Quantum Electron. 18(5), 925-930 (1982).

24. P. Loiko, X. Mateos, S. Y. Choi, F. Rotermund, J. M. Serres, M. Aguiló, F. Díaz, K. Yumashev, U. Griebner, and V. Petrov, "Vibronic thulium laser at $2131 \mathrm{~nm}$ Q-switched by single-walled carbon nanotubes," J. Opt. Soc. Am. B. 33(11), D19-D27 (2016).

25. P. Loiko, L. Zhang, J.M. Serres, Y. Wang, M. Aguiló, F. Díaz, Z. Lin, H. Lin, G. Zhang, E. Vilejshikova, E. Dunina, A. Kornienko, L. Fomicheva, V. Petrov, U. Griebner, W. Chen, and X. Mateos, "Monoclinic Tm:MgWO 4 crystal: Crystal-field analysis, tunable and vibronic laser demonstration," J. Alloy Compd 763, 581-591 (2018).

26. S. So, J. I. Mackenzie, D. P. Sheperd, W. A. Clarkson, J. G. Betterton, and E. K. Gorton, "A power-scaling strategy for longitudinally diode-pumped Tm:YLF lasers,” Appl. Phys. B 84(3), 389-393 (2006). 